\title{
IMAGINANDO LA IMAGEN EN TURISMO: un viaje de ida y vuelta
}

\author{
Agustín SANTANA TALAVERA \\ Universidad de La Laguna (España) \\ asantana@ull.es
}

\section{IMAGINING IMAGE ON TOURISM: A trip back and forth}

Resumen: Actualmente está ampliamente reconocido el papel que juega la imagen en el desarrollo del turismo y, especialmente, como elemento de diferenciación de un área de destino. Ello se refleja en gran media en la literatura, que vuelca su interés en identificar las variables que motivan la compra o incentivan el proceso de decisión. Sin embargo es extraña la referencia a procesos de retroalimentación o mecanismos de control de la imagen, así como a su creación. En este artículo se pretende exponer un modelo de comprensión de estos procesos.

Abstract: It is now widely recognized the role of image in tourism development, and especially as an element of differentiation of a target area. This is reflected in large media in the literature, which turns his interest in identifying the variables that motivate or encourage the purchase decision process. However it is strange reference to feedback processes or mechanisms of control of the image, as well as creation. This article aims to present a model of understanding of these processes.

Palabras clave: Turismo; Tiempo libre; Complejidad; Epistemología Tourism; Free time; Complexity; Epistemology 


\section{Introducción}

La competitividad, el dinamismo y la innovación son características propias del todo el sistema turístico. Es extraño no encontrar referencias a ellas en casi cualquier artículo académico, declaración institucional, proyecto de implementación o demanda de subsidios en que se encuentre implicada la actividad turística. La cultura-consumo del kleenex, lo de usar y tirar, es la principal responsable. El mercado exige renovación constante, de forma o contenido, en los productos y destinos, aunque a muchos se los nombre como tradicionales, históricos o "de siempre". Algunos de estos elementos renovados son obvios y su consumidor es partícipe, o cómplice gustoso, siempre que se cumpla con el condicionamiento estético al uso y se ofrezcan las comodidades que el momento turístico imponga. Este es el contexto de la "imagen del destino" que, rancia o imbuida de virtualidades y tecnologías, se crea y presenta a la pléyade de compradores y consumidores en un juego paradójico de continuidad y renovación, de familiaridad y contraste, de tradición (referencia al pasado reconstruido al gusto) y modernidad, y una presentación sin fisuras, como un todo sólo divisible si el destinatario lo desea o puede hacerlo por cuenta propia.

En los destinos, esos entes conformados como obras de ingeniería grupal con el único fin de la explotación económica sobre unos atributos temporalmente reales o quiméricos (paisajes pretendidos, infraestructuras de explotación, comunicaciones, etc. agrupados por su carácter territorial y de producto-servicio ofrecidos como experiencia integrada (Bigné, J.E.;Font, X. y Andreu, L., 2000)), confluyen actores con intereses definidos, ante el caos aparente, en un orden y definición operativa. Agrupándolos (Nash, D., 1996; Santana Talavera, A., 2003b) sin considerarlos en absoluto como homogéneos, la población residente (locales y foráneos asentados permanentemente), turistas y trabajadores foráneos (generalmente temporeros), a los que abría que añadir en no pocas ocasiones los grupos humanos asentados en áreas no necesariamente cercanas al destino turístico (área de influencia directa-visitada-e indirecta-zonas generadoras de turistas y trabajadores foráneos-). Múltiples grupos y un número indeterminado de culturas, subculturas y variaciones culturales, todos sujetos a posibles alteraciones - impactos emanados de las relaciones establecidas entre sí y con los productos ofertados - consumidos en el proceso turístico, además de otros no inmediatamente susceptibles a los cambios ocasionados por el turismo (cuadro 1).

\begin{tabular}{|c|c|c|}
\hline & SISTEMA TURÍSTICO & \\
\hline & PARTICIPANTES DIRECTOS & PARTICIPANTES INDIRECTOS \\
\hline $\begin{array}{l}\text { Sociedades de } \\
\text { origen }\end{array}$ & $\begin{array}{l}\text { Agentes de viaje - promotores } \\
\text { Turistas potenciales } \\
\text { (demanda supresiva - efectiva) } \\
\text { Fuerza de trabajo (+ empresariado) }\end{array}$ & $\begin{array}{l}\text { Grupos de población cercanos al turista } \\
\text { (familia, amigos, vecinos, etc.) } \\
\text { (+ empresariado) } \\
\text { Grupos no gubernamentales } \\
\text { (conservacionistas } \\
\text { y vinculados al desarrollo) }\end{array}$ \\
\hline Destino & $\begin{array}{l}\text { Políticos, gestores y administradores } \\
\text { Turistas ( } 1^{\text {a }} \text { vez/repetición) } \\
\text { Fuerza de trabajo foránea (+ empresariado) } \\
\text { Fuerza de trabajo local (+ empresariado) } \\
\text { Población residente en área de destino (locales y } \\
\text { foráneos con residencia permanente) }\end{array}$ & $\begin{array}{l}\text { Población residente cercana - fuera del } \\
\text { área destino } \\
\text { Políticos, gestores y administradores } \\
\text { Agentes de comercio (proveedores del } \\
\text { destino) } \\
\text { Grupos no gubernamentales } \\
\text { (conservacionistas } \\
\text { y vinculados al desarrollo) }\end{array}$ \\
\hline
\end{tabular}

Cuadro 1. Los actores del sistema turístico. Elaboración propia. 
Tal vez uno de los elementos más característicos de esta singular población de los destinos sea aquella falta de homogeneidad. Los imaginarios y sus referentes deben escogerse y diferenciarse para una clientela más o menos definida (nivel económico y educativo, rango de edad, procedencia sociocultural, demandas), pero a la vez se encuentran constreñidos por una serie de elementos físicos disponibles (atributos que quieren ser recursos que quieren ser productos) y una población empresarial y trabajadora que debe también adaptarse o mostrarse lo suficientemente flexible a la estacionalidad, los cambios de grupos de consumidores, las circunstancias laborales, etc. , además de una población residente que ha de ajustarse a los cambios que se suceden en su entorno. Un proceso en constante evolución, sujeto a cambios y ajustes en busca de la supervivencia turística, tal y como describió el ciclo de vida de los destinos Richard W. Butler (1980) y, actualizándolo, Tom Baum (1998).

Hoy por hoy, cuando se reconoce al turismo como una de las actividades económicas legales más importantes del planeta y su aportación a las economías nacionales y domésticas, existe un amplio consenso sobre la importancia que tiene la imagen como núcleo y motor del mismo. Buena muestra de ello es que sólo otro ítem, el de los impactos del turismo, compite con ella por el interés de las investigaciones desarrolladas. Excelentes trabajos como los de Gallarza, M.G.; Gil Saura, I. y Calderón García, H. (2002) o Frías, Rodríguez y Castañeda (2007) realizan un exhaustivo y considerado repaso a la bibliografía sobre la cuestión, y Baloglu y McCleary (1999), en un texto que ha marcado múltiples investigaciones posteriores, repasan los principales trabajos que se han desarrollado sobre ítems como el impacto de la visita, la familiaridad de la imagen, la relación entre la localización geográfica del turista y la imagen, medida de la imagen del destino, sus componentes y factores que la influyen, diferencia entre la imagen del turista (demanda) y la imagen que proyecta el destino, variaciones en la imagen según el propósito del viaje, relación entre variables socio-demográficas e imagen del destino, etc.

Los autores diferencian dos aproximaciones entre los estudios de estructura estática y los de estructura dinámica, según examinen las relaciones entre la imagen y el comportamiento del turista, los primeros, o el interés en la estructura y formación de la imagen del destino turístico. Siendo esta aproximación menos frecuente, se pretende en este texto contribuir a su discusión desde un punto de vista transdisciplinar.

\section{La globalidad de la imagen: definiciones, diseños y construcciones}

Desde la década de los noventa (Um, S. y Crompton, J.L., 1990; Gartner, W.C., 1993; Gallarza, M.G. et al., 2002) se tiende a considerar a la imagen como un constructo conceptual complejo y subjetivo (Bigne, J.E.;Sanchez, M.I. y Sanchez, J., 2001) en el que se funden emociones y razonamientos del consumidor con valoraciones que comparan la experiencia y el conocimiento sobre el destino. Esto es, un conjunto de representaciones mentales del conocimiento o creencias sobre los atributos físicos del destino turístico en su conjunto (componente cognitivo) combinadas con las valoraciones y sentimientos que despierta (componente afectivo) (Baloglu, S. y Brinberg, D., 1997). Este tipo de concepción se integra plenamente en una concepción cambiante de la imagen centrada tanto en los atributos físicos del área de destino como en la percepción por parte del consumidor-turista, que es quién, en último término, forma de todo ello un fotograma único cargado de sensibilidades, emociones y evaluaciones tanto cognitivas como afectivas (San Martín Gutiérrez, H.;Rodríguez del Bosque Rodríguez, I. y Vázquez Casilles, R., 2006). La imagen se torna pues individualizada (desde la definición aportada por Hunt, J.D., 1975)y marcada además por el rol de la actividad-pasividad que cumple todo turista en el desarrollo de su viaje (Mercille, J., 2005), circunscrita al consumo y marketing asociado.

Sin embargo, tomada así, el análisis de la imagen dejaría de lado a otros actores implicados en los procesos de diseño, formación y transmisión que van a fraguar el imaginario 
de ese destino. Es decir, el perfil que los grupos implicados en origen (locales y residentes, instituciones y políticos, empresarios e inversores, operadores y minoristas) proyectan de su área (territorio, historia, creencias, lengua, actividades, productos, etc.) en la construcción de la identidad del destino, lo que le identificará como tal (unicidad) o por comparación subjetiva con otros. La imagen en el sistema turístico es, prácticamente, el ítem que configura el destino y determina en gran medida la satisfacción y el recuerdo turístico, sobre todo por comparación en la experiencia de ser turista de un destino. Además, los efectos socioculturales sobre poblaciones locales de imágenes ajenas a sí mismas se dejan sentir a medio plazo, modificando patrones y rasgos conductuales, valores y relaciones, reconstruyendo las identidades locales (Franklin, A. y Crang, M., 2001).

Con todo y con ello, desde un enfoque sistémico procesual, parece necesario contemplar la imagen de manera global, lo cual conlleva diferenciar claramente entre el proceso de concepción, diseño y puesta en uso de los materiales que conforman la imagen construida para la venta (campañas en áreas de demanda y destino, acciones para fomentar la coincidencia entre lo expuesto y lo disponible, mejoras en los perfiles presentados para cada tipología de consumidores, ...) de los procesos de percepción e interiorización ("creación” y comparación individual). Se trata de abrir los esquemas y modelos de investigación a una doble vertiente de procesos retroalimentados e interconectados que metodológicamente permitan un estudio por pasos, con indicadores válidos en cada uno de ellos. Se contempla así un conjunto de siete sub-procesos de la imagen global interconectados pero divisibles operativamente tanto en su análisis como en su implementación (Cuadro 2).

\begin{tabular}{|c|c|c|}
\hline DESTINO & $\begin{array}{l}\text { CONSUMIDOR-TURISTA } \\
\text { (Diferenciación } \\
\text { repetidor) }\end{array}$ & Objetivo \\
\hline Imagen propia (residentes) (1) & \multirow{3}{*}{$\begin{array}{l}\text { PRE-COMPRA } \\
\text { Proceso de formación de la imagen } \\
\text { individualizada } \\
\text { - Global (indirecta, vaga) } \\
\text { - Otras fuentes } \\
\text { - Específica (turística) }\end{array}$} & \multirow[t]{3}{*}{ Atracción } \\
\hline Imagen construida para la venta (2) & & \\
\hline Imagen promocionada (3) & & \\
\hline \multirow{2}{*}{ Imagen recreada tour-operadores (4) } & Proceso de elección de destino & \multirow{2}{*}{ Venta } \\
\hline & $\begin{array}{l}\text { COMPRA } \\
\text { Imagen vendida (de refuerzo de compra. } \\
\text { Minoristas) (5) }\end{array}$ & \\
\hline \multicolumn{2}{|l|}{$\begin{array}{l}\text { CONSUMO } \\
\text { Imagen percibida (6) }\end{array}$} & Satisfacción \\
\hline \multicolumn{2}{|l|}{ Imagen compartida (recuerdo) (7) } & Fidelización \\
\hline
\end{tabular}

Cuadro 2. Modelo general de las imágenes en turismo (creación, consumo, recreación). Elaboración propia.

Se suele suponer que los atributos sobre los que una imagen de destino se asienta son en parte físicos (un entorno, unas infraestructuras, un clima) y en parte intangibles (la cultura, la amabilidad, la familiaridad, el buen hacer, la identidad). Desde finales de la década de los ochenta asistimos a la aparición en cascada de multitud de 'nuevos turismos', propiciados en su conjunto por las nuevas condiciones y exigencias del mercado, esto es, competitivi- 
dad, flexibilidad y segmentación. La práctica totalidad de los nuevos productos se presentan, y a veces analizan, como "una forma diferente de practicar el turismo" y la máxima es la consecución para el cliente de una experiencia satisfactoria, la experiencia de lo 'auténtico' en la naturaleza, la cultura, la gente o una combinación de las mismas. Sobre la pléyade de denominaciones comerciales, destacan sobre manera las conocidas como ecoturismo, turismo étnico, turismo rural y turismo cultural, este último de aplicación más amplia. Su desarrollo se lleva a cabo, preferiblemente, en áreas no congestionadas poblacionalmente (parajes deshabitados o con muy bajo nivel de ocupación humana, entornos rurales no urbanos o pequeñas poblaciones concentradas), pero pueden incluirse tour monumentalesarquitectónicos o museísticos por ciudades o presentarse como subconjuntos de ofertas en los nuevos turismos de masas. Es en este contexto de nuevas búsquedas en el que las poblaciones residentes, antes actores pasivos, pasan a formar parte consustancial de la imagen construida para la venta y se torna importante la imagen propia, aquella percibida por los residentes de sí mismos y del área en el que conviven.

Mientras que el estudio de la imagen propia rara vez es incorporado a los análisis turísticos, si lo han sido sus actitudes frente al turismo (Getz, D., 1994; Ryan, C. y Montgomery, D., 1994; Lindberg, K. y Johnson, R.L., 1997; Lawson, R.W.;Williams, J.;Young, T. y Cossens, J., 1998; Smith, M.D. y Krannich, R.S., 1998), dado que ello podría afectar en gran medida a la imagen percibida. La incorporación de la imagen propia puede aportar veracidad a las campañas, identificando atributos y evitando performances innecesarias, pero también estableciendo límites (espaciales, cualitativos, cuantitativos o temporales) (Kozlowski, J., 1986) al desarrollo o a la explotación turística de las áreas. Se entiende que la imagen propia puede no ser única, en tanto que dependerá de los diferentes grupos socioculturales y socioeconómicos que conformen la población local del área y los niveles de integración de la población foránea con aquellos y entre sí. Pero en tanto que es influida por las imágenes ofertadas al turismo, a largo plazo puede simplificarse en gran medida. En una situación ideal gran parte de la imagen propia deberá ser reflejada, al menos en la imagen construida para la venta y, finalmente, en la imagen vendida, pero esto rara vez ocurre. Las representaciones ideales que cada cual -cada grupo- tenga de sí mismo y el medio son difícilmente encajadas por la demanda de un lugar mítico, el paraíso en sus múltiples y cambiantes versiones, que pueda coexistir en los países generadores de turistas. Por este motivo, no es extraño encontrar imágenes construidas y promocionadas sobre recursos virtuales, pasajeros o demasiado adornados, como tampoco lo es la inclusión como atrezzo de elementos tan variables como el clima o los eventos sociales (Santana Talavera, A., 2003b).

En tales circunstancias, la imagen propia, lo cotidiano, por la eficiencia económica y organizativa para la población residente y las exigencias de la lógica de mercado, se concibe en una copia cuya calidad se mide en términos de su adaptación para el consumo. Se convierte en un argumento para su venta como imagen construida, mostrando las facilidades de acceso, inocuidad y exotismo, en el modelo clásico, o la peligrosidad, riesgo, desamparo y aventura, en las más refinadas formas de diseño en las nuevas experiencias turísticas más o menos cargadas de sensacionalismo según nos desplacemos de la "autenticidad" a la "realidad" comercializada turísticamente. Motivaciones, expectativas y actividades multidimensionales (Villa, A.D., 2001) que se reflejan en complejidad e intangibilidad de la imagen.

La imagen construida para la venta suele venir marcada por los intereses de las instituciones y empresariado del área, así como, en menor medida, por los residentes. Es usual encontrarse con tres estrategias más o menos limitadas: (1) una política conjunta y participativa (colaborativa) de todos o parte de los implicados en el diseño de tal imagen (actores directos en el destino), en la selección de atributos, conjunción de productos y sus referentes físicos y emocionales sobre la identidad del destino ; (2) una selección más o menos interesada realizada en torno a los productos y actividades disponibles en el área agrupados por bloques temáticos o sub-áreas territoriales, y (3) un conglomerado de iniciativas más o 
menos compatibles y generalmente exógamas que tienden a sobrevalorar atributos del destino como recursos, suponiendo su demanda (común, aunque no en exclusiva, en formas de imagen que pretenden impulsar el turismo cultural, etnoturismo, etc).

Las políticas turísticas basadas en la sostenibilidad (aquellas que atienden las necesidades de los turistas actuales sin comprometer la posibilidad de usufructo de los recursos por las generaciones futuras, World Comission of Environment and Development, 1987) de los destinos turísticos recomiendan cada vez con mayor ahínco la primera de las opciones, en tanto que, al soportarse sobre la imagen propia no sólo minora los efectos antedichos, sino que además provee al área de herramientas dinámicas de respuesta a los cambios del mercado sin graves alteraciones en su estructura social y económica. Esta estrategia evita en gran medida que los bienes y espacios cotidianos sean transformados en productos de representación, tratando de ajustar el necesario atractivo (o efecto decisorio) de los atributos y recursos sin deslegitimarlos culturalmente. En no pocas ocasiones, el medioambiente, la cultura misma o una selección no neutral de los mismos, ha sido objetivados y despersonalizados, sacados de contexto, a fin de obtener un producto presentable como auténtico, fuera de tiempo, que debía infundir la idea de experiencia inolvidable y única (Markwell, K., 2001) para su consumidor y, a la vez, ser repetible y estandarizado para el conjunto.

La segunda, y más frecuente, de las estrategias de instauración de la imagen construida suele venir determinada por especialistas y aplicada a destinos en una fase intermedia de su ciclo de vida (Butler, R.W., 1980). No se suele tratar tanto de grandes innovaciones como alteraciones y añadidos sumatorios a campañas de promoción anteriores. En términos generales se tratan de mantener ventajas competitivas modificando las atribuciones de recursos y productos, combinando actividades e introduciendo infraestructuras. Como refiere Schouten (1995), una buena interpretación está basada en conexiones realizadas con ideas y experiencias que ya sean familiares y sobre el aumento de la curiosidad de los visitantes. Esta forma de diversificación de la imagen construida puede ser fácilmente reconducida hacia las estrategias participativas cuando se aplica a pequeños destinos, pero se encuentra con serios problemas operativos y conflictos de intereses cuando se trata de áreas amplias y consolidadas.

Por último, la tercera estrategia, radica en la adaptación de las 'realidades' a sus destinatarios (residentes y turistas), pudiendo ofrecer una apropiación estética y una experiencia emocional en un lapso de tiempo extremadamente corto. Este modo, combinado o no con la participación, puede contemplarse especialmente en las nuevas áreas turísticas surgidas en la remodelación del sistema de los años noventa. En el peor de los casos, cuando la exogamia de la imagen construida ha imperado y los mercados no han respondido, los impactos socioeconómicos han sido realmente importantes. Y ello sin presencia de turistas propiamente dichos (generación de expectativas y compromiso de capitales), y rompiendo así el esquema conceptual de la imagen y del sistema turístico. La ventaja de este tipo de reinterpretaciones de la imagen construida del destino es que permiten la entrada de múltiples productos individualizados con o sin cobertura de la marca o la identidad del destino.

Suponiendo cualquiera de los casos anteriores, las ideas que componen tal diseño han de ser materializadas en diversas campañas de promoción, formándose lo que se ha denominado imagen promocionada. Un diseño marcado para la comercialización, en gran medida, por la demanda y los creativos de la campaña sobre unos atributos más o menos presentes en el área y por la imagen construida.

Contribuyendo a ella sobre todo las instituciones regionales y locales, y en mucha menor medida el empresariado, es distinta de la anterior. A través del análisis de las recientes campañas promocionales es observable como el 'lider creador' (persona o grupo) de las organizaciones-instituciones turísticas imprime su marca, tratando de consolidar (a menudo por periodos legislativos) proyectos de destino que expresen un determinado nivel de calidad (condicionado por la competencia y la identidad del destino), honestidad (no engañar 
al cliente), preparación (profesionalidad en los servicios y productos ofertados) y capacidad de respuesta a los valores y deseos de un conjunto o segmento del mercado destinatario (tendencia al 'turismo a la carta'). El cumplimiento de objetivos (número, frecuencia y tipo de turistas) y la madurez organizativa (persistencia) determinarán en gran medida la solidez del proyecto y, dentro de las limitaciones e incertidumbres propias del sistema turístico, su durabilidad efectiva (tiempo exitoso en el mercado).

Aunque rara vez ocurren cambios drásticos, el paso de la imagen construida a la promocionada obliga a pequeños ajustes para adaptarse a las necesidades de comercialización ante unos segmentos del mercado concretos (turistas potenciales), las variaciones en la demanda y la competencia de otros destinos. Esta forma que toma la imagen es, a la vez, enormemente flexible (permitiendo ciertas alteraciones al combinar productos o potenciar nuevos recursos) y definitoria del destino ante el consumidor (lo cual limita la característica anterior). La imagen promocionada, con un importante componente físico, tangible, que se refleja en panfletos, folletos, pegatinas, carteles y otras formas de material publicitario, es la que se puede encontrar junto a otros aderezos en las ferias turísticas dirigidas, sobre todo, a los tour-operadores y minoristas o agentes de viajes, si bien en algunas ocasiones es posible que se realicen grandes campañas para llegar al gran público.

La importancia general de este componente de la imagen global radica en su posición como motivador consciente e inconsciente que anima al individuo a sumarse a la corriente turística, mediante estímulos simbólicos que evocan estados anímicos determinados (relajación, aventura, descubrimiento, diversión, etc.). En un ámbito más concreto, su objetivo es contribuir a consolidar la decisión de compra sobre un destino y tipo de turismo determinado. En este punto, es atribuible a la imagen promocionada tanto el papel de generadora y reforzadora de estereotipos sobre el destino (de carácter grupal) (Echtner, C.M. y Ritchie, B.W., 1991; Gallarza, M.G. et al., 2002) como de promotora de expectativas (de carácter individual) (Litvin, S.W. y MacLaurin, D.J., 2001; Litvin, S.W. y Ng Sok Ling, S., 2001) sobre el área, los productos promocionados y las emociones causadas por su consumo. Sin embargo, ha de entenderse que la imagen de los destinos turísticos es incremental, esto es, no directamente sustituible de una a otra campaña promocional, por lo que áreas con una imagen negativa o degradada tendrán que empeñar mucho más esfuerzo, recursos y tiempo (Fakeye, P.C. y Crompton, J.L., 1992) que otros con una imagen positiva fuerte para ser incluidos entre el pool de destinos elegibles en los procesos de toma de decisión (Frías, D.M. et al., 2007).

Sin embargo, la determinación del destino electivo viene condicionada también por otros factores, fundamentalmente, económicos (costos, descuentos y posibilidades de pago o endeudamiento), temporales (estacionalidad, coincidencia con periodos no laborables o escolares) e incidentales (presencia de menores o ancianos, climatología, seguridad, tiempo de viaje, etc.). Si bien es cada vez más frecuente que las áreas de destino se promocionen a sí mismas (se propongan como elegibles) no lo es tanto que se encarguen de los procesos de venta de sus propios productos (tipo centrales de reservas), copando el mercado de la intermediación turística algunos grupos de operadores multinacionales (agentes mayoristas) (Hasta un 55\% de los viajes vacacionales contratados en el Reino Unido en 2001, según Parra López, E.;Melchior Navarro, M. y Ramos Domínguez, Á., 2003).

En su adaptación a la demanda, generación de la misma y mejor composición de negocio (Martín de la Rosa, B., 2003), los tour-operadores pueden combinar tanto productos de un mismo destino como productos de áreas diferenciadas, en incluso varios destinos con todos sus productos, cuando no crear productos (sobre todo de servicios) totalmente nuevos que se insertarán en un o unos destinos determinados. Se reconoce así una imagen re-creada que puede ser proyectada no homogéneamente al mercado por los diferentes operadores, en paralelo a la imagen promocionada que inyectarán las instituciones, organismos y, escasamente, empresas (Andreu, L.;Bigné, J.E. y Cooper, C., 2000, se refieren a la imagen 
proyectada que en el esquema conceptual propuesto hemos subdividido metodológicamente en imagen promocionada e imagen re-creada).

En este proceso el tour-operador acerca el viaje al consumidor, posibilitando su adaptación y compra, sobre todo por primera vez, de un producto (conjunto de bienes y servicios) específico. Éste llega al cliente a través de las agencias de viaje (agentes minoristas), que puede modificar sustancialmente, en positivo o en negativo, las imágenes e impresiones que hasta ahora ha creado sobre el destino. El agente de viaje no suele conocer de primera mano ni el destino, ni los productos, ni la imagen promocionada (mucho menos la construida para la venta), con lo que en último término interpreta y oferta al posible consumidor un destino-producto(s) partiendo del material aportado por el tour-operador (imagen re-creada) y la propia experiencia-habilidad del vendedor. En la práctica, la información aportada por los agentes de viaje introducen nuevamente algunas variaciones, no poco importantes, en la imagen, conformando la imagen vendida. Ambas imágenes, recreada y vendida (correspondientes a los canales de distribución como sujetos activos), son las que consolidan expectativas sobre el cliente-turista potencial que adquiere el disfrute, temporalmente limitado, de unos productos constituidos por bienes, servicios, actividades, territorio, clima, paisaje, cultura, etc., o lo que es lo mismo, paga por una apropiación temporal y pactada de una porción del destino y las experiencias en él reproducibles.

Usualmente, las imágenes proyectadas (promocionadas, re-creada y vendida) se definen a partir de una serie de variables o códigos (adaptado de Ronai, M., 1976, refiriéndose al paisaje). Estos son:

1. El código psicológico: a partir del cual se buscan figuras o representaciones que evoquen emociones o revivan experiencias.

2. El código estético: el juego de colores, distancia, textura, etc. que presenta el entorno como una obra de arte antrópica o física.

3. El código inconsciente: atribuyendo al destino deseado adjetivos que orienten al receptor en forma de mensaje subliminal.

4. El código mítico: referencia a lo irracional, la fantasía, el Aparaíso perdido@, con ciertas características de sus gentes pero resaltando siempre, y según el destinatario, su carácter arcaico o su progreso.

5. El código estratégico: resalta la posición privilegiada atendiendo a los valores que se quieren destacar.

6. El código geográfico/humano: exposición épica de características físicas como geomorfología, clima, etc. dando especial importancia a los contrastes. Del mismo modo se trata a los habitantes del área y se exponen los rasgos que se le pretenden.

7. El código infraestructural: la comunicación con el destino pero haciendo énfasis en los vectores propios de la comodidad para la vacación y/o viaje, remarcando la posibilidad de evasión o, en su caso, las ideologías medioambientalistas.

Pudiendo operativamente ser simplificadas y descompuestas en cuatro categorías de elementos:

1. funcional (movilidad, infraestructuras, posibilidades de relación o actividad);

2. pintoresco y grandioso (escenas peculiares con cualidades plásticas, monumentalidad y paisajismo);

3. emotivo (evocación de sentimientos) y

4. único (atributos tangibles o intangibles exclusivos de un área y sólo de ella).

En teoría, la disposición del destino-espectáculo, donde todo lo que acontece puede ser construido y regulado como atractivo, concluye con su presentación a la población con- 
sumidora con una uniformidad de estilo, léxico y diversidad temática (según los grupos de destinatarios) e iconos representativos estándar. Dependiendo de los productos y actividades turísticas específicas (quedan al margen el reality tourism, voluntourism y formas semejantes), se da una valoración fundamentalmente estética del área ocultando las posibles contradicciones, tanto entre el espacio y el resto de la sociedad anfitriona, como entre los grupos sociales que la componen, ofreciendo una aparente armonía.

\section{La globalidad de la imagen: individualidad y recuerdo}

El sujeto de la mirada, el turista-actor, aprehende la imagen como parte de sus procesos cotidianos y como un objeto de la cultura que visita (normalmente oculta tras el velo de la actividad turística) en un ejercicio de codificación, interpretación y valoración comparativa desde su modo de vida y cultura de origen, mediado por el sistema turístico. La espacialidad y la temporalidad de lo cotidiano son limitadas en el destino, cuando no suspendidas a priori, reforzando el carácter inmanente (esencial) de lo creado para el disfrute y es este el lugar en el que la imagen se completa. Así pues, la imagen percibida se muestra como un conjunto total (Assael, H., 1984) de creencias, ideas e impresiones del lugar visitado (Crompton, J.L., 1979), yuxtapuestas a los estereotipos y expectativas acumuladas antes de la visita.

En este sentido la imagen individualizada como representación mental pasa por un largo proceso de formación que puede iniciarse incluso antes de que el cliente potencial tenga la motivación para viajar. Esto puede suceder indirectamente en tanto en cuanto los individuos tienen acceso a informaciones globales que van siendo tematizadas según intereses personales, de grupo, sociales, políticos, medioambientales, etc., creándose estados de opinión y conocimientos específicos. Es decir, preconfigurando imágenes y estereotipos simplificados (la imagen orgánica propuesta por Gunn, C.A., 1972; desarrollada por Fakeye, P.C. y Crompton, J.L., 1991) según sus características sociodemográficas (género, edad, nivel educativo y socioeconómico, principalmente). Cierto es que este tipo de información indirecta suele ser vaga e imprecisa, pero predispone a los individuos a la recepción de discursos más elaborados turísticamente (imagen inducida según los mismos autores o imagen proyectada, como se ha nombrado en el presente texto) y, consecuentemente, a una mayor probabilidad de aparición de motivaciones (Castaño, J.M.;Crego, A. y Moreno, A., 2006) y selección de un tipo de destino concreto.

Baloglu y McCleary (1999) establecen que el transcurso de la imagen pasa por el conocimiento directo o indirecto de los atributos objetivos de un lugar sobre el que se generan emociones, diferenciando entre factores estímulo (fuentes de información según cantidad y tipo, experiencia previa y distribución) y factores personales (psicológicos --valores, motivaciones y personalidad-- y sociales -características sociodemográficas). En la aplicación empírica de este modelo, Beerli y Martín (2004) desarrollan una categorización de los factores estímulo, distinguiendo entre fuentes secundarias (información básicamente percibida antes de la visita, distinguiendo entre orgánica, inducida y autónoma) y fuentes primarias (formada durante la visita en cuestión), determinando la importante influencia de los primeros (sobre todo de las fuentes de información inducida -canales de distribución - y autónomas - guías de viaje-) como factores determinantes de la elección del destino y de la imagen global percibida.

Si bien las características individuales del turista van a condicionar en mayor o menor medida la aprehensión de la imagen del destino, y su evaluación, los estereotipos que en la actualidad son difundidos por los medios de comunicación de masas (Bardón Fernández, E., 1991) la desvirtúan y tratan de forzar al individuo a adaptar su propia observación/participación a la imagen que resulta más conveniente al negocio turístico (más rentable o menos costosa). Y algo parecido, pero de consecuencias más duraderas sucede a las poblaciones de destino. Todo parece indicar que la experiencia como turista y la procedencia sociocultural 
de origen los clientes (Santana Talavera, A., 1997), que no directamente su nacionalidad (Beerli, A. y Martin, J.D., 2004), influirá tanto en los aspectos cognitivos como afectivos de la imagen percibida. Ambos aspectos asientan su relevancia en la capacidad y conocimiento para la comparación de imágenes, atributos, servicios y experiencias del destino con las vividas anteriormente en sus viajes o en la cotidianeidad, además de con las expectativas previas al viaje. En este sentido, las impresiones o emotividades siempre son subjetivas (y difícilmente cuantificables) y se encuentran separadas, aunque relacionadas, de los elementos tangibles del destino turístico. Sobre estos, casi específicamente, se realizan atribuciones que son confrontadas valorativamente, poniendo de manifiesto no sólo la semejanza o diferencia señalada, sino tendiendo además a la generalización por analogía.

Así, las entrevistas realizadas (Cruz Modino, R.d.l., 2004; Cruz Modino, R.d.l., 2007; Pinto da Silva Santos, R., 2007; Rodríguez Darias, A.J., 2007) muestran que, aunque el turista en el destino está continuamente en un ejercicio de contraste (incluso con lo más familiar), cualquier elemento no esperado o anómalo será incluido en el balance afectivo y evaluado positiva o negativamente. Ante la semejanza en facetas, cualidades o relaciones con una situación anteriormente experimentada, el individuo desarrollará emotividades y formas de comportamiento como si respondiera a aquella situación inicial, afectando a la imagen percibida en el momento actual. Al fundamentarse en impresiones, este proceso constituye uno de los motivos por los que la imagen percibida del destino turístico pueda alejarse (Gartner, W.C., 1993) de lo que la población residente y los agentes permanentes del destino puedan considerar, dicho con toda cautela, una imagen objetiva o real.

La confrontación por parte del turista de la imagen percibida (manifestación del Encuentro (Santana Talavera, A., 2003a)) con el juego de expectativas no predictivas y estereotipos tomados de las imágenes orgánica y proyectada, deriva en un juicio valorativo (cognitivoafectivo) de su experiencia. Es lo que se conoce como satisfacción en turismo (Westbrook, R.A., 1987; Echtner, C.M. y Ritchie, B.W., 1991; Bigne, J.E. et al., 2001). Siendo el objetivo final del turismo la maximización de beneficios - negarlo es parte de la utopía-, la principal preocupación de los destinos es obtener un alto nivel de satisfacción de su clientela y, a ser posible, fidelizar tanto a estos turistas como a sus allegados. Pero, como se ha señalado, son muchos factores pueden distorsionar la imagen percibida (Teye, V.;Sönmez, S. y Sirakaya, E., 2002) y con ello afectar a los niveles de satisfacción (entendidos en un gradación bipolar no satisfacción-satisfacción continua) e insatisfacción (de igual forma no insatisfaccióninsatisfacción) (Westbrook, R.A., 1987). Por ello se hace necesario determinar no sólo tales niveles de manera global sino descomponerlos, al menos, en las mismas variables y factores empleados para el análisis de la imagen y la generación de expectativas.

La experiencia del turista ha de entenderse de esta manera como un conjunto de vivencias que se inicia en las motivaciones conscientes, se desarrollan en el viaje, estancia en el destino y regreso a su normalidad, concluyendo con la configuración del recuerdo, su comunicación y la comparación propia con sus semejantes (imagen compartida).

\section{Operavitización del modelo propuesto}

El análisis del modelo general de la imagen formulado presenta la importante dificultad de su multidimensionalidad de espacios y actores, en tanto en cuanto, no sólo implica al destino turístico en sí mismo sino que ha de contemplar las culturas y variaciones culturales implicadas y los procesos de cambio (perspectiva diacrónica). La complejidad se hace patente al repasar los diferentes diseños de investigación empleados, en las que la sola determinación de variables ha sido objeto de grandes discusiones. Gallarza et al. (2002) revisan con bastante exhaustividad las diferentes metodologías empleadas en los estudios sobre imagen (entendida esta, en nuestro esquema, como proyectada y percibida), clasificándolas según su capacidad para cuantificar los resultados y, en su caso, la técnica utilizada para su 
captura y medición. Como para casi cualquier proceso inserto en el sistema turístico, la visión de una disciplina en exclusiva no puede más que cercenar los resultados y ofrecer conclusiones sesgadas y parciales. La imagen, como ningún otro elemento, ha de ser analizada con las epistemologías y herramientas metodológicas (y técnicas) de múltiples disciplinas humanísticas, sociales y económicas.

La mayoría de los estudios de caso revisados se decantan por el uso de cuestionarios tipo (encuestas) que son considerados como técnicas estructuradas (batería de atributos fijado de antemano por el investigador) o no estructuradas (descripciones libres) para la medición de la imagen de los destinos turísticos, si bien a partir de finales de la década de los noventa se hace cada vez más común la conjunción de ambas. Esta combinación se ha mostrado muy fructífera para el análisis de la imagen percibida del destino y la medición tanto del cumplimiento de expectativas como de las motivaciones para realizar el viaje, en tanto en cuanto facilitan la cuantificación y la predicción estadística. Generalmente, las variables o conjunto de atributos son determinados a través de la revisión de otros estudios realizados y disponibles en la literatura académica, además de los resaltados a partir de grupos de discusión con expertos y entrevistas en profundidad con personajes clave. Estos suelen ser, en la mayoría de los casos, ordenados en una encuesta en el que se formulan cuestiones gradadas en una escala de Likert de 5 a 7 posiciones, a los que se añaden preguntas abiertas de corta respuesta y un apartado de comentarios. Los turistas que formarán la muestra son categorizados según intereses académicos e investigadores (casi nunca siguiendo alguna de las tipologías al uso) y los resultados serán procesados-medidos a través de diferentes procedimientos estadísticos.

Tradicionalmente la antropología se ha desempeñado sobre grupos y territorios más o menos estables, utilizando como técnica principal la observación participante (trabajo de

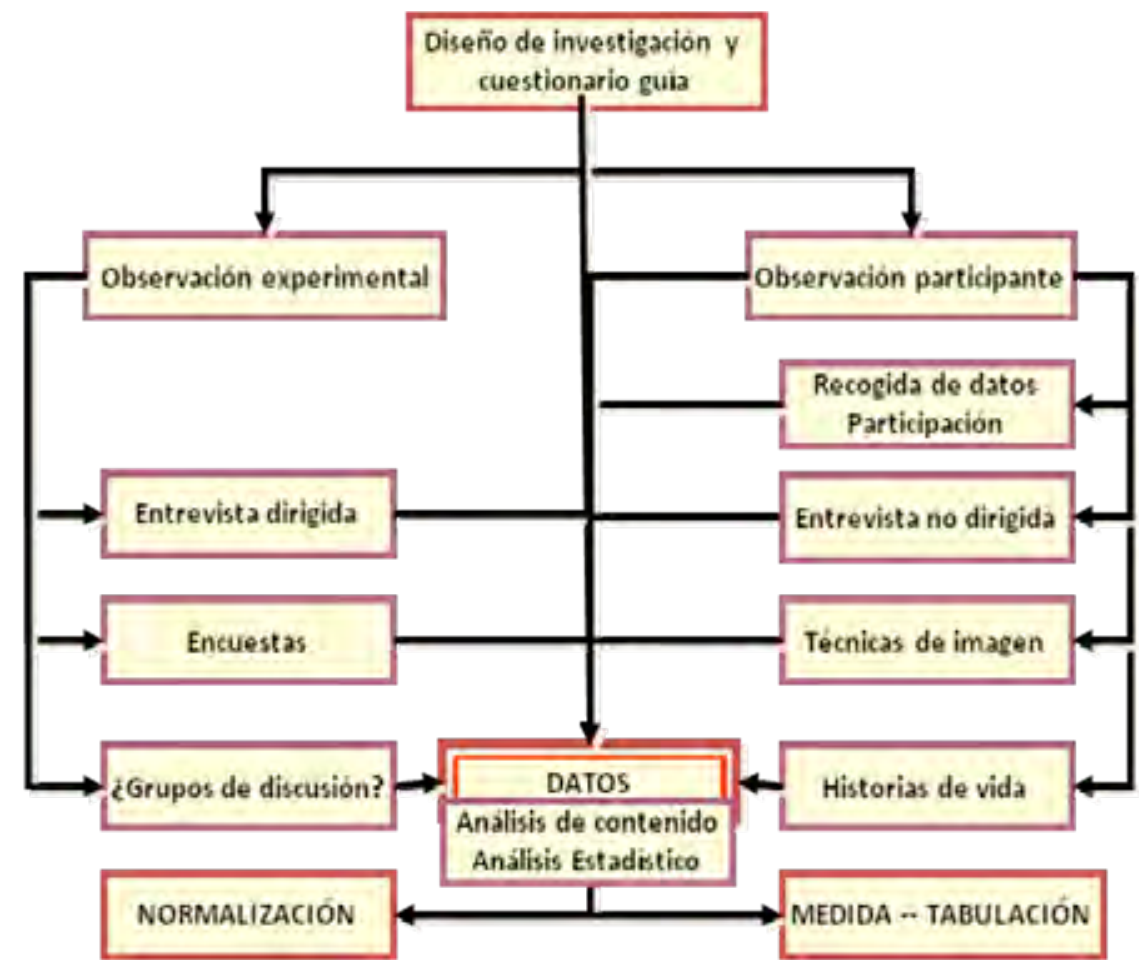

Cuadro 3. Propuesta de aplicación de técnicas de investigación al estudio de la imagen del destino. 
campo). Al enfrentar el estudio de una población de alto dinamismo (sobre todo turistas y trabajadores foráneos en el destino), la técnica ha tenido que ser adaptada partiendo de análisis tipo survey que identifiquen y delimiten lo más posible una tipología de agentes (básicamente expuestos como actores del sistema turístico) sobre los que se realice una acotación. Pero el principal componente inicial de la investigación viene de la mano de la observación de tales grupos en su contexto. De este modo, una investigación ideal sobre la imagen global tomaría como unidades de observación tanto las principales áreas emisoras de turistas como el destino mismo. Dada la dificultad que ello representa, en tanto que dimensión y características del equipo de investigación y costes económicos y temporales, las unidades de observación suelen circunscribirse al área de visita, es decir, el destino se torna en única unidad de estudio a través de la observación de los grupos participantes (subdivididos según espacios, actores, actividades).

La observación participante (interacción social no obstrusiva entre el investigador y los informantes) y la observación experimental (en la que el observador actúa provocando situaciones), siempre guiadas por el diseño de la investigación, pueden arrojar luz especialmente sobre comportamientos y reacciones de los actores, además de en el análisis e la imagen global. En su seno, y como parte de las técnicas empleadas para la obtención de datos, se emplearán las entrevistas dirigidas y no dirigidas, técnicas visuales (análisis de representaciones), historias de vida, grupos de discusión y las propias encuestas (tal y como se describieron arriba) (cuadro 3) para el grupo de variables expresadas en el cuadro 4.

Metodológicamente, para el caso concreto del estudio de la imagen propia, este se inicia determinando los grupos presentes, su rango y representatividad. A partir de entrevistas estructuradas y cuestionarios se presta especial atención a la importancia sobre sus atributos lingüísticos, territoriales y socioculturales que han de determinar referentes tangibles (naturales o creados, desde la gastronomía hasta la arquitectura) e intangibles (historias, representaciones, simbolización). El ejercicio del análisis comparativo de los diferentes grupos residentes en destino, más su rango y la sociabilidad de los grupos, indicará los elementos comunes, las disonancias perceptivas y los rasgos adaptables a la estructura del mercado turístico (convertibles en productos). Se trata pues de un ejercicio previo al desarrollo del destino turístico, mientras que si ya se encuentra establecida su identidad, la técnica mostrará las posibles distorsiones de esta imagen respecto a la proyectada. En este caso, y tras el proceso antedicho, se aplican además sobre las poblaciones residentes e interesados los mismos atributos que para determinar la imagen percibida por parte de los turistas, lo cual mostrará las similitudes o disconformidades con las imágenes propia, construida y proyectada.

Para el estudio, y verificación de eficacia, de la imagen promocionada (especialmente las campañas institucionales) y la imagen compartida se toman los datos a partir de los atributos señalados en el cuadro 4, pero de nuevo ampliando el rango de actores. En estas cuestiones, el análisis de los datos se realiza a partir de los siete códigos (psicológico, estético, insconsciente, mítico, estratégico, geográfico/humano e infraestructural) en un análisis de contenido (texto, fotos, video, etc.). Ello ayudará a discernir qué estímulos se producen a partir de los mismos, la adecuación a la imagen propia, la generación de expectativas, la construcción del recuerdo y la diseminación de los mismos, etc. Una herramienta escasamente utilizada es el análisis de los evocadores del recuerdo, tales como las representaciones pictóricas tomadas en el destino, artefactos de cualquier tipo (arena, piedras, maderas, ticket de entrada a espectáculos, o cualquier otro elemento tangible que pueda ser relacionado con una actividad, emoción o sentimiento) y los souvenirs o compras de artículos que necesarios realizadas. 


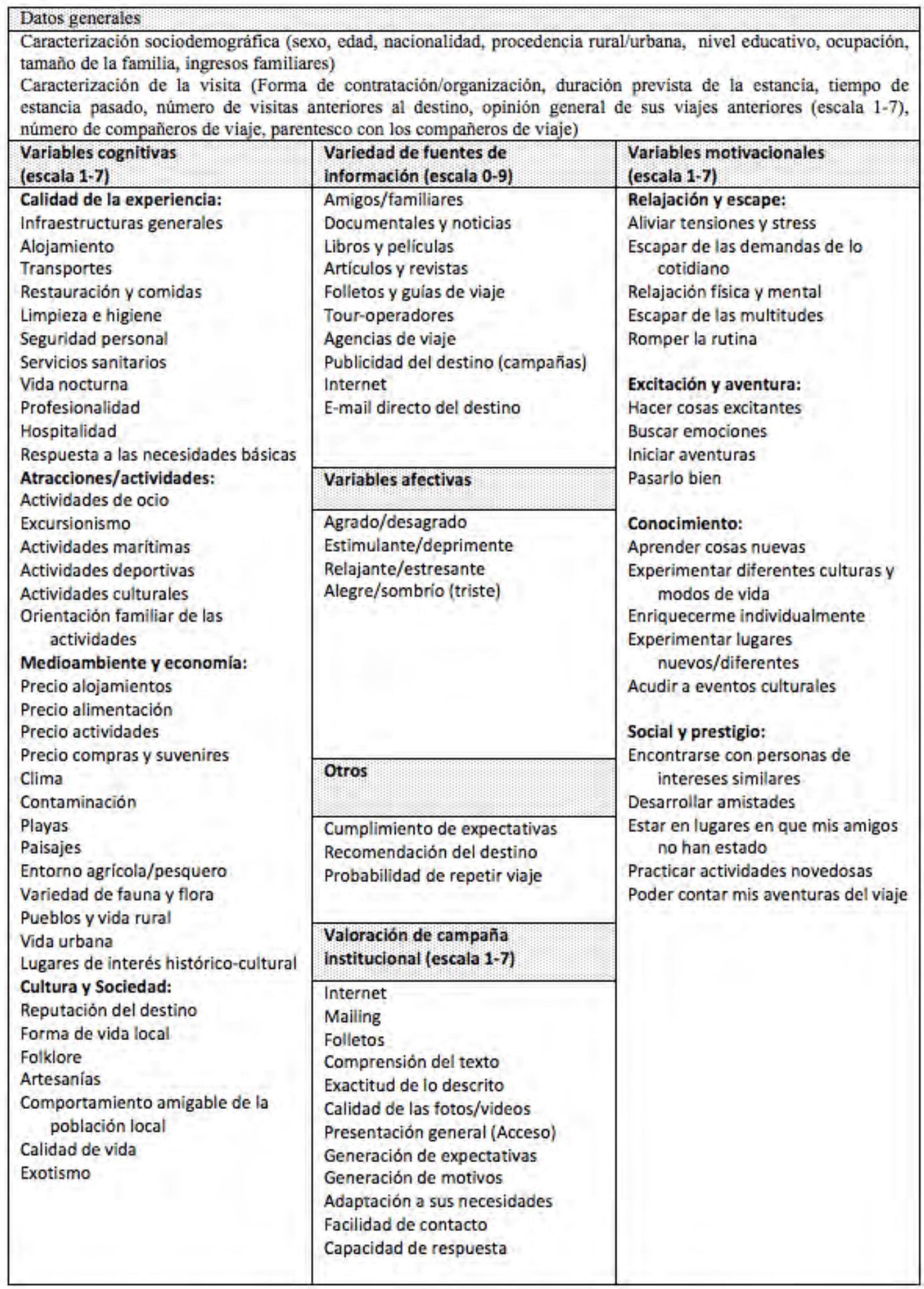

Cuadro 4. Atributos considerados para su inclusión en las encuestas a los diferentes actores del destino. Fuente: elaboración propia sobre (Echtner, C.M. y Ritchie, B.W., 1991; Echtner, C.M. y Ritchie, B.W., 1993; Baloglu, S. y Brinberg, D., 1997; Baloglu, S. y McCleary, K.W., 1999; Baloglu, S., 2001; Baloglu, S. y Mangaloglu, M., 2001; Beerli, A. y Martin, J.D., 2004; San Martín Gutiérrez, H. et al., 2006). 


\section{Conclusión}

Algunos se refieren a estos tiempos como los propios para volver a imaginar el pasado neorromántico, el de las buenas gentes que admiraban al salvaje, por supuesto de lejos, y además obtenían prestigio por hacerlo. Unos tiempos caracterizados, al menos en occidente, en los países que precisamente emiten el mayor número de turistas, por el tiempo libre reconocido como derecho, unos niveles de gasto y capacidad de endeudamiento individual y del núcleo doméstico jamás vistos hasta ahora. Estos son los condicionantes que nos insertan en la Aldea Global, aquella que impulsa a mirar cotidianamente más allá de las pequeñas fronteras, y así, por una amenaza de pérdida inmediata, a concentrarse en los localismos, a opositar en la hibridación cultural, esto es en la conjugación de ideas, de esencias y relaciones materiales, de significados y estructuras fundidos al unísono.

El edén, históricamente presente y casi universal, antaño soñado y contado como vergel, camaleónico Olimpo cultural, adaptante y adaptable según los rigores y rubores de cada sociedad y cada momento histórico, se encuentra hoy invadido, repleto de hamacas para reposar el momento, gentes que ver como actores y cámaras fotográficas que demuestran y recuerdan el paso por allí inmortalizado en la banal instantánea. Ni la guerra, ni el hambre, ni el ansia reproductiva habían movido a la humanidad como lo hace la actividad turística, y ni en la mejor literatura romántica se soñó con la enorme variedad de ensoñaciones, de estereotipos más o menos filtrados que hicieran de los otros parte del paraíso particular, casi uno por cada turista y por cada uno de los que desearían ser turistas.

Principalmente es achacable a la actividad turística esta red de expectativas, pero como los efectos, los impactos, no sólo a ella. Es casi imposible distinguir cuánto le debe al sistema turístico, y su incesante generación de imágenes sobre productos y destinos, de otras influencias tales como la televisión y el cine, con programaciones y secuencias sin una intencionalidad declarada en la motivación del viaje; cuánto al efecto demostración que nos impulsa a conjugar nuestros intereses con los de otros, a sentir aquello que otros dicen que han sentido; cuánto a la iniciativa y creatividad individual. Pero los estudios de caso parecen indicar que, con todo, el resultado de estas y otras variables, es una imagen que se infiltra en la cultura occidental, que se asume como cotidiana y nos mueve a convertirnos en pasajeros, en huéspedes temporales del sistema, cada uno agrupado según expectativas, motivaciones, esperanzas y deseos de experimentar nuestro paraíso particular.

Esa imagen, casi culturalmente aprendida como proceso, genera recuerdos no vividos, espacios deseados y para el deseo, promesas de encuentro con otros, los iguales en menor grado, los diferentes sobre todo, ocultando las desigualdades en principio, realzándolas cuando el producto así lo requiere.

Lejos del buen salvaje sometido a los dominios del Imperio, los actores del sistema turístico se vuelven parte activa en la manipulación de los signos, produciendo, reproduciendo y consumiendo, según el papel representado, a modo de simulacros atemporales, las formas culturales que se consideran al efecto comercializadas. Los consumidores del producto turístico, cómplices en el consumo de la autenticidad, han sido acreditados con el incremento de su rol activo en la creación de significados. Habría que ver quién ofrece estos significados o al menos las pautas básicas para inferirlos o generar 'innovadoramente' estas nuevas versiones de significados ya al uso en otras áreas. La originalidad no es precisamente lo que prima en los destinos turísticos, sean estos culturales o de masas o de cualquier otro tipo, lo cual induce a creer que realmente existen los arquitectos de la hibridación.

En este texto se ha presentado una manera algo diferente de contemplar la formación de la imagen global, una parte de aquellas hibridaciones, a fin de orientar algunas investigaciones en curso y contribuir a la discusión sobre las herramientas teóricas y metodológicas con el convencimiento de que es posible llegar a establecer un marco de entendimiento, crítica y discusión en el sistema turístico y los procesos que en él se desenvuelven. 


\section{Bibliografía}

Andreu, L.; Bigné, J.E. y Cooper, C. (2000): "Projected and perceived image of Spain as a tourist destination for british travellers". Journal of Travel \& Tourism Marketing, 9(4): 47-67.

Assael, H. (1984): Consumer behavior and marketing action. Boston: Kent Publishing.

Baloglu, S. y Brinberg, D. (1997): “Affective images of tourism destination”. Journal of Travel Research, 35(4): 11-15. No disponible

Baloglu, Seyhmus (2001): "Image variations of Turkey by familiarity index: informational and experiential dimensions". Tourism Management, 22: 127-133. 51003132 pdf

Baloglu, Seyhmus y Mangaloglu, Mehmet (2001): "Tourism destination images of Turkey, Egypt, Greece, and Italy as perceived by US-based tour operators and travel agents". Tourism Management, 22: 1-9.51003131 pdf

Baloglu, Seyhmus y McCleary, Ken W. (1999): “A model of destination image formation”. Annals of Tourism Research, 26(4): 868-897. 5100 Disponible en papel

Bardón Fernández, E. (1991): "El paisaje en la oferta turística recreativa". Estudios Turísticos, 112: 27-54.

Baum, Tom (1998): "Taking the exit route: extending the tourist area life cycle model". Current Issues in Tourism, 1(2): 167-175. pdf

Beerli, Asuncion y Martin, Josefa D. (2004): "Factors influencing destination image". Annals of Tourism Research, 31(3): 657-681. pdf

Bigné, J. E.; Font, Xavier y Andreu, L. (2000): Marketing de destinos turísticos: análisis y estrategias de desarrollo. Madrid: ESIC Editorial. BULL

Bigne, J. Enrique; Sanchez, M. Isabel y Sanchez, Javier (2001): "Tourism image, evaluation variables and after purchase behaviour: inter-relationship". Tourism Management, 22(6): 607616. $51003191 \mathrm{pdf}$

Butler, R.W. (1980): "The concept of a tourism area cycle of evolution: implications for management resources". Canadian Geographer, 24(1): 5-12. No disponible

Castaño, José Manuel ; Crego, Antonio y Moreno, Alfredo (2006): "Factores psicosociales y formación de imágenes en el turismo urbano:

un estudio de caso sobre Madrid". PASOS. Revista de Turismo y Patrimonio Cultural, 4(3): 287-299.

Crompton, John L. (1979): "Motivations for pleasure vacation". Annals of Tourism Research, 6(4): 408-424. Comprobar disponibilidad

Cruz Modino, Raquel de la (2004): "Patrimonio Natural y Reservas Marinas". PASOS. Revista de Turismo y Patrimonio Cultural, 2(2): 179-192.

Cruz Modino, Raquel de la (2007): “ Proteger el mar, conservar las culturas: Turismo y pesca en la Reserva Marina Punta de La Restinga - mar de Las Calmas (El Hierro, Islas Canarias) y en el Área Natural Protegida de las Islas Medas (Girona, Cataluña)”, Investigación en curso. La Laguna, Tenerife: Universidad de La Laguna.

Echtner, C. M. y Ritchie, Brent W. (1991): "The meaning and measurement of destination image". The Journal of Tourism Studies, 2(2): 2-12.

Echtner, C. M. y Ritchie, Brent W. (1993): "The measurement of destination image: an empirical assessment". Journal of Travel Research, 31(4): 3-13.

Fakeye, Paul C. y Crompton, John L. (1991): "Image differences between prospective, first-time, and repeat visitors to the Lower Rio Grande Valley”. Journal of Travel Research, 30(2): 10-16. Comprobar disponibilidad

Fakeye, Paul C. y Crompton, John L. (1992): “Importance of socialization to repeat visitation”. Annals of Tourism Research, 19(2): 364-367. Comprobar disponibilidad

Franklin, Adrian y Crang, Mike (2001): “The trouble with tourism and travel theory?" Tourist Studies, 1(1): 5-22. En 51003204

Frías, Dolores $\mathrm{M}^{\mathrm{a}}$; Rodríguez, Miguel A. y Castañera, J. Alberto (2007): "Internet vs. travel agencies on pre-visit destination image formation: An information processing view". Tourism Management, En prensa. pdf carpeta imagen

Gallarza, Martina G.; Gil Saura, Irene y Calderón García, Haydée (2002): "Destination image. Towards a conceptual framework". Annals of Tourism Research, 29(1): 56-78. 51003383 pdf 
Gartner, W. C. (1993): "Image formation process". Journal of Travel and Tourism Markqting, 2(2/3): 191-215. No disponible

Getz, D. (1994): "Residents' attitudes towards tourism: A longitudinal study in Spey Valley, Scotland". Tourism Management, 15(4): 247-258. 51002515 pdf

Gunn, C.A. (1972): Vacationscape. Designing tourist regions. Washington, DC: Taylos and Francis/ University of Texas.

Hunt, John D. (1975): "Image as a factor in tourism development". Journal of Travel Research, 13(3): 1-7. no disponible

Kozlowski, J. (1986): Threshold approach in urban, regional and environmental planning: theory and practice. St. Lucia: University of Quennsland Press.

Lawson, R. W.; Williams, J.; Young, T. y Cossens, J. (1998): “A comparison of residents' attitudes towards tourism in $10 \mathrm{New}$ Zealand destinations". Tourism Management, 19(3): 247-256.

Lindberg, K. y Johnson, R. L. (1997): "Modeling resident attitudes toward tourism.” Annals of Tourism Research, 24(2): 402-424. ISI:A1997WL80800009 5100 Disponible en papel

Litvin, S. W. y MacLaurin, D. J. (2001): "Consumer attitude and behavior". Annals of Tourism Research, 28(3): 821-823. ISI:000168930200017 5100 Disponible en papel

Litvin, Stephen W. y Ng Sok Ling, Sharon (2001): “The destination attribute management model: an empirical application to Bintan, Indonesia". Tourism Management, 22(5): 481-492. $51003186 \mathrm{pdf}$

Markwell, Kevin (2001): “'An intimate rendezvous with nature? Mediating the tourist-nature experience at three tourist sites in Borneo". Tourist Studies, 1(1): 39-58. En 51003204

Martín de la Rosa, Beatriz (2003): "La imagen turística de las regiones insulares: las islas como paraísos". Cuadernos de Turismo, 11: 127-137. pdf image

Mercille, Julien (2005): "Media effects on image: The Case of Tibet". Annals of Tourism Research, 32(4): 1039-1055. pdf

Nash, Dennison (1996): Anthropology of tourism. Oxford: Pergamon. 51003271

Parra López, Eduardo ; Melchior Navarro, Mercedes y Ramos Domínguez, Ángel (2003): “Análisis e impacto de los touroperadores y las agencias de viaje en el transporte turístico: nuevas tendencias en Canarias”. PASOS. Revista de Turismo y Patrimonio Cultural, 1(2): 217-229.

Pinto da Silva Santos, Roque (2007): “Padrones actitudinales de gestores en el turismo en Ilhéus, Brasil”, Investigación en curso. La Laguna, Tenerife: Universidad de La Laguna.

Rodríguez Darias, Alberto Jonay (2007): “Turismo en áreas protegidas. El caso de los parques rurales de Tenerife (Islas Canarias, España)”, Investigación en curso. La Laguna, Tenerife: Universidad de La Laguna.

Ronai, M. (1976): "Paysages". Hérodote, 1: 125-159. 51001486 pdf

Ryan, Ch. y Montgomery, D. (1994): "The attitudes of Bakewell residents to tourism and issues in community responsive tourism". Tourism Management, 15(5): 358-369. 51002503 pdf

San Martín Gutiérrez, Héctor; Rodríguez del Bosque Rodríguez, Ignacio y Vázquez Casilles, Rodolfo (2006): "Análisis de la imagen en turismo mediante técnicas estructuradas y no estructuradas: implicaciones competitivas para los destinos turísticos”. Revista Asturiana de Economía, RAE, 35: 69-91. pdf imagen

Santana Talavera, Agustín (1997): Antropología y turismo. ¿Nuevas hordas, viejas culturas? Barcelona: Ariel. 51002893

Santana Talavera, Agustín (2003a): "Jugant a ser amfitrions: trobades i impactes en el sistema turístic". Revista d'etnologia de Catalunya, 22: 46-53. pdf

Santana Talavera, Agustín (2003b): "Mirando culturas: la antropología del turismo". En Rubio Gil, Á. (Ed.), Sociología del turismo (pp. 103-125). Barcelona: Ariel. En 51003441

Smith, M. D. y Krannich, R. S. (1998): “Tourism dependence and resident attitudes". Annals of Tourism Research, 25(4): 783-802. En 51003026

Teye, Victor; Sönmez, Sevil y Sirakaya, Ercan (2002): “Residents' attitudes toward tourism development". Annals of Tourism Research, 29(3): 668-688.

Um, Seoho y Crompton, John L. (1990): “Attitude determinants in tourism destination choice”. Annals of Tourism Research, 17(3): 432-448. 51000873 pdf 
Villa, Aurora D. (2001): "El turismo cultural o la mercantilización de la cultura". In Arqueología, N.C.V.d.A.y. (Ed.), Congreso Virtual de Turismo 2001. http://www.naya.org.ar. 51003244 pdf

Westbrook, R.A. (1987): "Product/consumption-based afective responses and postpurchase processes". Journal of Marketing Research, 24(3): 258-270.

\section{5}

